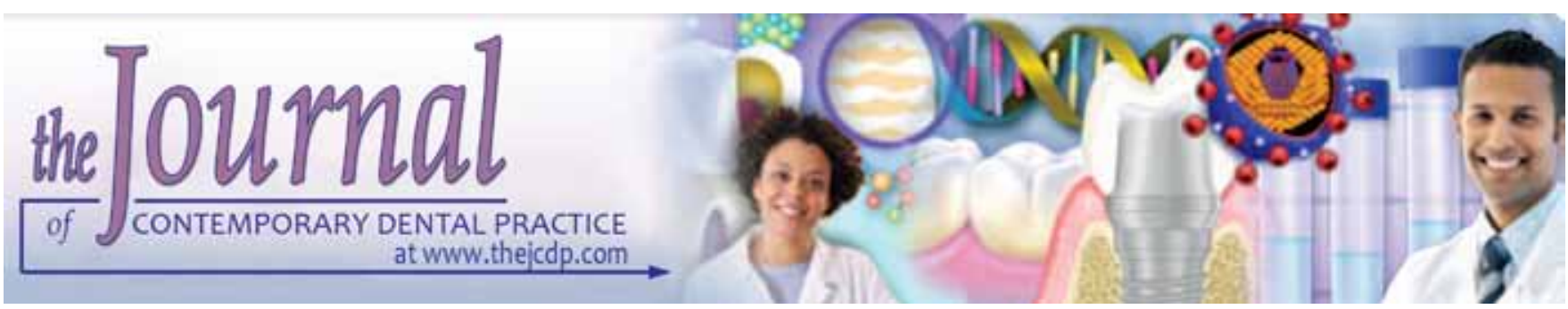

\title{
Evaluation of Bone Thickness and Density in the Lower Incisors' Region in Adults with Different Types of Skeletal Malocclusion using Cone-beam Computed Tomography
}

${ }^{1}$ Maram MN Al-Masri, ${ }^{2}$ Mowaffak A Ajaj, ${ }^{3}$ Mohammad Y Hajeer, ${ }^{4}$ Muataz S Al-Eed

\begin{abstract}
Objectives: To evaluate the bone thickness and density in the lower incisors' region in orthodontically untreated adults, and to examine any possible relationship between thickness and density in different skeletal patterns using cone-beam computed tomography (CBCT).
\end{abstract}

Materials and methods: The CBCT records of 48 patients were obtained from the archive of orthodontic department comprising three groups of malocclusion (class I, II and III) with 16 patients in each group. Using OnDemand $3 \mathrm{D}^{\circledR}$ software, sagittal sections were made for each lower incisor. Thicknesses and densities were measured at three levels of the root (cervical, middle and apical regions) from the labial and lingual sides. Accuracy and reliability tests were undertaken to assess the intraobserver reliability and to detect systematic error. Pearson correlation coefficients were calculated and one-way analysis of variance (ANOVA) was employed to detect significant differences among the three groups of skeletal malocclusion.

Results: Apical buccal thickness (ABT) in the four incisors was higher in class II and I patients than in class III patients $(p<0.05)$. There were significant differences between buccal and lingual surfaces at the apical and middle regions only in class II and III patients. Statistical differences were found between class I and II patients for the cervical buccal density (CBD) and between class II and III patients for apical buccal density (ABD). Relationship between bone thickness and density values ranged from strong at the cervical regions to weak at the apical regions.

Conclusions: Sagittal skeletal patterns affect apical bone thickness and density at buccal surfaces of the four lower incisors'

${ }^{1-4}$ Department of Orthodontics, University of Damascus Dental School, Damascus, Syrian Arab Republic

Corresponding Author: Mohammad Y Hajeer, Associate Professor, Department of Orthodontics, University of Damascus Dental School, Damascus, Syrian Arab Republic, Phone: 00963113141343, e-mail: myhajeer@gmail.com roots. Alveolar bone thickness and density increased from the cervical to the apical regions.

Keywords: Alveolar bone density, Alveolar bone thickness, Class I malocclusion, Class II malocclusion, Class III malocclusion, Cone-beam computed tomography.

How to cite this article: Al-Masri MMN, Ajaj MA, Hajeer MY, Al-Eed MS. Evaluation of Bone Thickness and Density in the Lower Incisors' Region in Adults with Different Types of Skeletal Malocclusion using Cone-beam Computed Tomography. J Contemp Dent Pract 2015;16(8):630-637.

Source of support: Nil

Conflict of interest: None

\section{INTRODUCTION}

The position of the lower incisors and its relation to the supporting bone that surround them has great importance on orthodontic diagnosis and treatment planning. ${ }^{1}$ The management of different skeletal patterns depends on the amount of possible buccal or lingual movement of incisors, especially in patients with severe skeletal discrepancies or orthodontic-surgical cases, as in these cases moving the incisors is limited by the anatomy of the alveolar bone and the status and integrity of periodontal tissues. $^{3}$

Orthodontists should take into consideration the quantity of alveolar bone in the area around the lower incisors, as moving the teeth through the bone depends on bone remodeling mechanism and tissue response to orthodontic forces; understanding bone mineral density (BMD) helps explain the reason how bony dehiscence or fenestration occurs, and also helps to know the differences in bone loss and apical resorption between adults and young people, as young alveolar bone has more blood vessels and spongious bone than in adults. ${ }^{4,5}$ 
Before commencing orthodontic treatment, the treating orthodontist should be aware of the available amount of bony support around the lower anterior teeth in order not to violate the relatively small buccolingual dimensions of the alveolar process. ${ }^{6,7}$ The buccolingual movements of the lower incisors are usually limited because of the quality and quantity of bone in this region. 6,8 Thus, a prior knowledge of the amount of bony support is demanded to avoid bone dehiscence and increase in periodontal problems.

Several methods have been used to assess bone thicknesses; lateral cephalogram was used to measure labiolingual bone width but the measurements were not accurate when compared with physical measurements of the actual specimens, because all structures overlap on each other on cephalometric images. ${ }^{9}$

With the advent of cone-beam computed tomography (CBCT) in dentistry, teeth and supporting bone can be evaluated with a low dose of radiation as compared to other diagnostic medical imaging techniques, such as computed tomography (CT) scanning. ${ }^{10}$ The CBCT images allow clinicians to evaluate the size of the alveolar bones without the disadvantages of conventional radiographs, as these images give accurate measurements as a result of the high clarity, with the possibility of extracting cephalogram images with accuracy and reliability. ${ }^{11-13}$

Several studies in the orthodontic literature have focused on the relationship between the thickness of anterior alveolus and the labiolingual position of upper and lower incisors; the relationship between different skeletal jaw positions and anterior alveolar thickness has also been evaluated. . $^{6,8,14-16}$

In the study of Kim et al, vertical alveolar bone levels and alveolar bone thickness were compared between lower and upper incisors in surgical skeletal class III patients; they found that the amount of bone loss at the lower incisors was greater than that of the uppers, and lingual bone thickness was greater at the upper incisors and smaller at the opposing teeth. ${ }^{17}$

When Baysal et al compared alveolar bone thickness between skeletal class I and II malocclusions, the observations were that buccal alveolar bone thicknesses in class I patients were significantly greater than those in class II patients, and that the buccal apical alveolar bone thickness was greater than lingual in class II malocclusions. ${ }^{18}$

Earlier studies about the density of the lower alveolar bone were made with the help of pyknometry, microradiography or histoquantification. ${ }^{19}$ At present, bone density can be evaluated by different methods, as different tissue types absorb different amount of radiation. Measuring density by using CT was first introduced in 1970s. ${ }^{20}$ Bone density is measured in Hounsfield units
(HU). ${ }^{21}$ The accuracy and reproducibility of this method have been already found to be very good. ${ }^{22}$

It seems that there is no published work in relation to the assessment of alveolar bone density around the four lower incisors in different skeletal patterns with healthy periodontal tissues. The only study that assessed alveolar bone density was published by Nauert et al. ${ }^{7}$ However, the study evaluated bone support (including thickness and density) at different levels of the lower incisors' roots in adults with a near-to-normal occlusion using conventional CT imaging. They found moderate association between bone thickness and density at cervical regions and no correlation at the apical regions.

Therefore, the aim of the current study was to evaluate and compare the alveolar bone thickness and density in the cervical, middle, and apical regions of the buccal and lingual surfaces of the four lower incisors in adult patients with different sagittal skeletal patterns using CBCT.

\section{MATERIALS AND METHODS}

Study design and setting: This was a retrospective radiological study for descriptive and analytic purposes and was carried out at the department of orthodontics at University of Damascus dental school. The CBCT records were selected from the archive of orthodontic department between May 2014 and Jan 2015. Before study commencement, the required sample size was estimated using G*Power 3.1.7 software. ${ }^{23}$ For a power of $80 \%$, a significance level of $5 \%$ and an effect size of $0.40 \mathrm{~mm}$ (based on the results of a previous report) to detect a significant difference in the alveolar bone thickness between the three groups [using one-way analysis of variance (ANOVA)], 16 patients were found to be required for each group. ${ }^{18}$

The sampling frame included patients who had CBCT images and fulfilled the following inclusion criteria: (1) age between 18 and 25, (2) no congenitally missing or extracted teeth, (3) no previous orthodontic treatment, (4) mild to moderate crowding, and (5) acceptable oral hygiene without periodontal conditions. In total, 168 CBCT images were found. The skeletal relationship of the included patients was first evaluated using CBCTderived cephalograms (Fig. 1) and the evaluation was based on the ANB angle and Wits appraisal. ${ }^{24,25}$ Class I patients were those with an ANB angle between 0 and $4^{\circ}$ and an AO-BO value of 0 to $4 \mathrm{~mm}$, class II patients were those with ANB greater than $4^{\circ}$ and an $\mathrm{AO}-\mathrm{BO}$ greater than $4.5 \mathrm{~mm}$, whereas class III patients were those with ANB less than $0^{\circ}$ and an AO-BO value smaller than $0.5 \mathrm{~mm}$. Disproportionate stratified random sampling was employed to create thee groups of sagittal skeletal relationships with 16 patients in each group. Table 1 


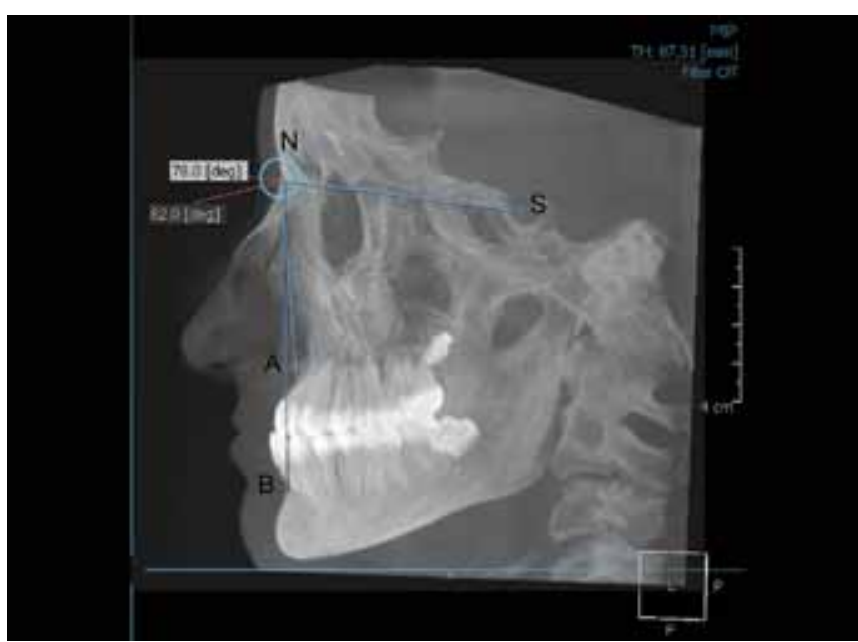

Fig. 1: The constructed lateral cephalogram. Landmarks and planes were traced using OnDemand 3D

shows the descriptive statistics of the sample using some of the variables measured on the CBCT-derived cephalograms.

\section{Cone-beam Computed Tomography Image Acquisition}

All CBCT images were scanned at the same imaging apparatus, i.e. SCANORA ${ }^{\circledR} 3 \mathrm{D} \times$ Device (Soredex, Tuusula, Finland), with $15 \mathrm{~mA}, 85 \mathrm{kV}$, 40-second exposure time and isotropic voxel size of $0.25 \times 0.25 \times 0.25 \mathrm{~mm}$. Files were saved as digital imaging and communications in medicine (DICOM) format and the images were viewed through OnDemand 3D ${ }^{\circledR}$ software (CyberMed, Finland).

\section{Cone-beam Computed Tomography Analysis}

Sagittal slices in each $\mathrm{CBCT}$ image were extracted to examine the alveolar bone thickness and density around
Table 1: Descriptive statistics of the included patients in this study

\begin{tabular}{llll}
\hline Variable & $\begin{array}{l}\text { Class I } \\
(n=16)\end{array}$ & $\begin{array}{l}\text { Class II } \\
(n=16)\end{array}$ & $\begin{array}{l}\text { Class III } \\
(n=16)\end{array}$ \\
\hline ANB & $2.55 \pm 0.90$ & $5.9 \pm 1.32$ & $-2.43 \pm 1.81$ \\
Bjork's sum & $392.30 \pm 5.04$ & $395.34 \pm 5.81$ & $393.65 \pm 6.82$ \\
Sn-GoMe & $32.81 \pm 5.04$ & $34.58 \pm 5.46$ & $32.49 \pm 6.89$ \\
MM & $24.43 \pm 4.14$ & $26.58 \pm 6.46$ & $25.40 \pm 7.95$ \\
Lower incisors' & $94.01 \pm 4.36$ & $97.30 \pm 4.88$ & $85.26 \pm 7.19$ \\
inclination & & & $10 / 6$ \\
$\begin{array}{l}\text { Male(n)/ } \\
\text { female(n) }\end{array}$ & $5 / 11$ & $8 / 8$ & \\
\hline
\end{tabular}

ajork's sum is the sum of the following angles: NSAr, SArGo and ArGoMe; $\mathrm{MM}$ is the angle between the maxillary and mandibular planes; $\mathrm{Sn}-\mathrm{GoMe}$ is the angle between anterior cranial base and the mandibular plane; Lower incisors' inclination is the angle between the long axis of the lower incisor and the mandibular plane

each of the four lower incisors. To ensure a consistent procedure, each CBCT was oriented along the long axis of the incisor, bisecting the pulp and canal in the sagittal and coronal planes, and in a labial-lingual direction in the axial plan (Fig. 2). This orientation was repeated for each incisor to do all measurements of thicknesses and densities.

The measurements were undertaken in sagittal view of each lower incisor. First, the thickness of the alveolar bone in both surfaces (buccal and lingual) was measured for each of the four lower incisors in the cervical, middle, and apical regions. This was achieved by using the ruler which was positioned perpendicular to the tooth long axis from the root surface (without measuring the periodontal ligament) to the most external surface of the cortical bone (Fig. 3). 'Middle level' was determined by putting the ruler parallel to the long axis of the incisor and identifying half of the distance from the cementum enamel junction (CEJ) to the incisor apex.

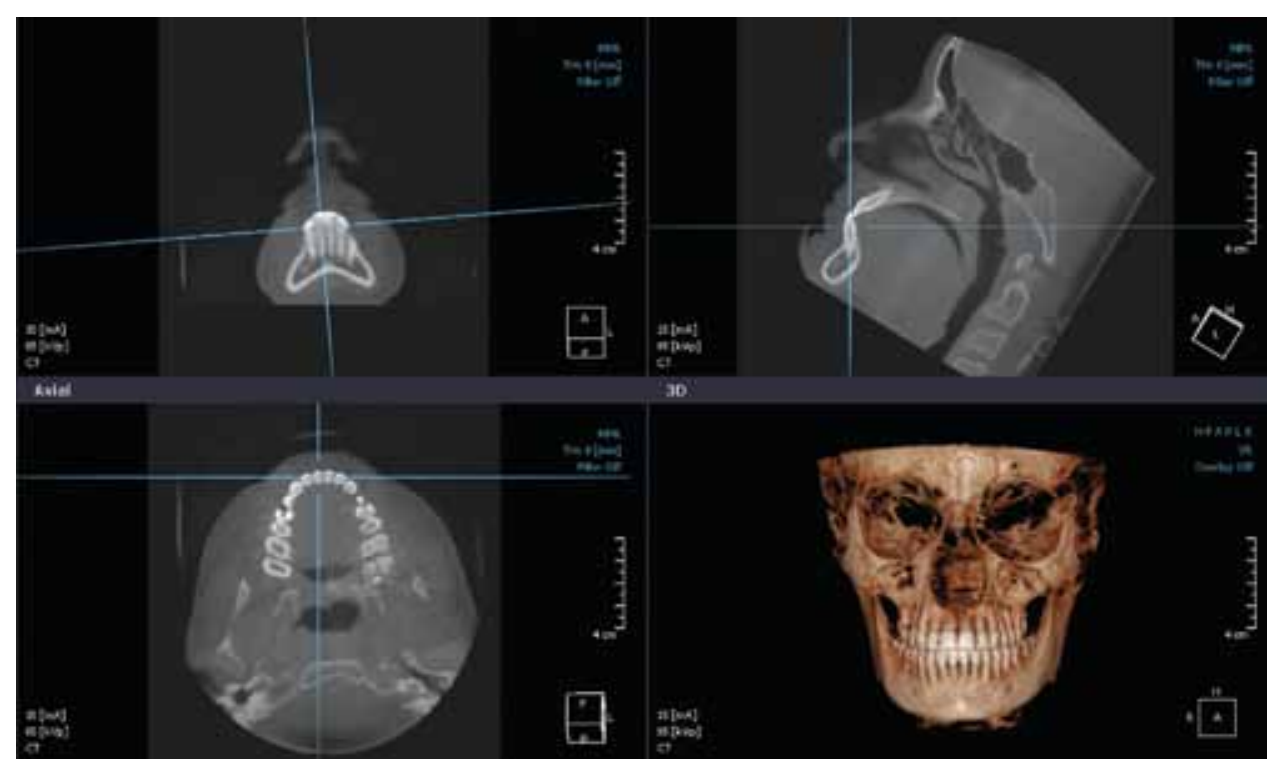

Fig. 2: The sagittal, coronal and axial orientation of lower left incisor on the CBCT image. The slice should bisect the pulp canal of this tooth prior to measuring 


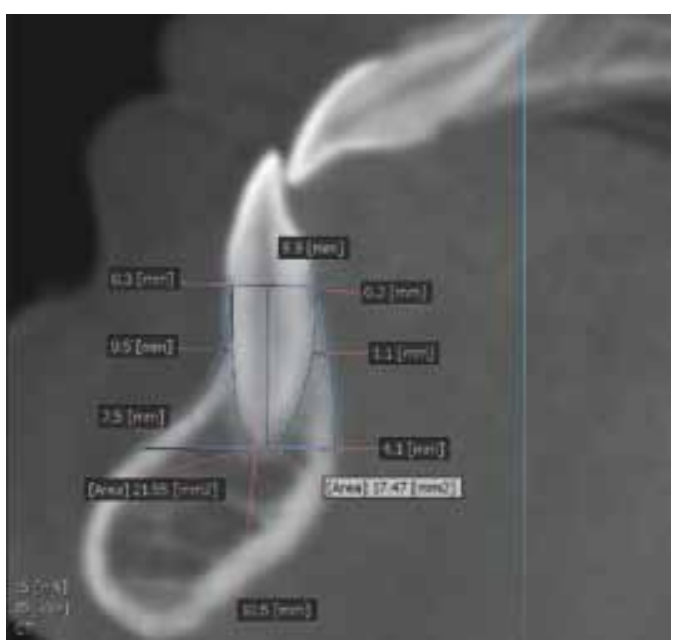

Fig. 3: Sagittal sectioning of the left central incisor (with three levels that were traced) to measure thickness and density from the buccal and lingual sides

The main value of bone density was measured buccally and lingually at the same levels (cervical, middle, and apical). Bone density was measured in Hounsfield units. ${ }^{26}$ The alveolar bone was classified according to Zarb and Lekholm into the following categories: D1, compact cortical bone, $\geq 1200 \mathrm{HU}$; D2, crestal cortical bone and coarse trabecular bone underneath, 700 to $1200 \mathrm{HU}$; D3, porous crestal layer of cortical bone and fine trabecular bone, 350 to $700 \mathrm{HU}$, and $\mathrm{D} 4$, fine trabecular bone, 100 to $350 \mathrm{HU}$. The registration of the various tissue types is based on differences in absorbed radiation.

\section{STATISTICAL ANALYSIS}

All statistical analyses were performed with SPSS v. 20 (SPSS Inc., Chicago, IL, USA). Kolmogorov-Smirnov tests were applied to assess the normality of the distributions. All data were normally distributed, so parametric tests were deemed appropriate. One-way ANOVA was used to compare bone thickness and density for buccal and lingual surfaces between the three groups of skeletal malocclusion. The significance level was set at 0.05 .
Pearson correlation coefficients were calculated to check whether an association between the bone thickness and density values existed in both lingual and buccal surfaces at different levels.

\section{Error of the Method}

Ten CBCT images were selected randomly and were remeasured after a 2-week interval. Paired t-tests and intraclass correlation coefficients (ICCs) were performed to assess systematic and random errors. There were no significant differences between the two measuring times, and reliability analysis confirmed an excellent agreement between two readings with the highest ICC value of 0.978 for middle lingual density (MLD) and the lowest ICC value of 0.876 for apical lingual thickness (ALT) measurement, as seen in Table 2.

\section{RESULTS}

The descriptive and inferential statistics of the studied variables are presented in Tables 3 to 6 .

\section{Alveolar Bone Thickness}

No statistically significant differences were found between the three groups regarding alveolar bone thicknesses at the buccal and lingual surfaces of the four lower incisors except for the apical buccal thickness (ABT), which was greater in the class II and I patients than in the class III patients $(\mathrm{p}<0.001)$. Also, cervical buccal thickness (CBT) was significantly lower in the class II patients compared to class I patients ( $p<0.05$, Table 3 ). Bone thickness increased from the cervical to the apical regions. The majority of lower incisors (89\%) had a less than $1 \mathrm{~mm}$ of bone thickness on the labial surfaces up to the middle regions.

Statistically significant differences were found when comparing buccal and lingual bone thicknesses as shown in Table 4 . There were statistically significant differences

Table 2: Assessment of the intraobserver reliability and error of the method (in $\mathrm{mm}$ )

\begin{tabular}{|c|c|c|c|c|c|c|c|}
\hline \multirow[b]{2}{*}{ Variable $^{a}$} & \multicolumn{2}{|c|}{ 1st measurement } & \multicolumn{2}{|c|}{ 2nd measurement } & \multirow[b]{2}{*}{$I C C^{b}$} & \multirow[b]{2}{*}{ Mean difference } & \multirow[b]{2}{*}{$p$-value ${ }^{c}$} \\
\hline & Mean & $S D$ & Mean & $S D$ & & & \\
\hline MBT & 0.45 & 0.25 & 0.44 & 0.18 & 0.889 & 0.01 & 0.863 \\
\hline $\mathrm{ABT}$ & 2.58 & 0.97 & 2.48 & 0.89 & 0.944 & 0.10 & 0.481 \\
\hline MLT & 0.94 & 0.43 & 0.96 & 0.42 & 0.929 & -0.02 & 0.813 \\
\hline ALT & 3.09 & 1.09 & 3.21 & 0.80 & 0.876 & -0.13 & 0.673 \\
\hline MBD & 958.35 & 192.92 & 939.10 & 210.70 & 0.974 & 19.25 & 0.103 \\
\hline ABD & 1024.9 & 225.70 & 1023.30 & 218.90 & 0.945 & 1.62 & 0.963 \\
\hline MLD & 800.05 & 278.80 & 765.00 & 219.00 & 0.978 & 35.05 & 0.165 \\
\hline ALD & 991.55 & 277.27 & 987.40 & 221.14 & 0.967 & 4.12 & 0.887 \\
\hline
\end{tabular}

${ }^{a}$ ABT: Apical buccal thickness; MBT: Middle buccal thickness; ALT: Apical lingual thickness; MLT: Middle lingual thickness; MBD: Middle

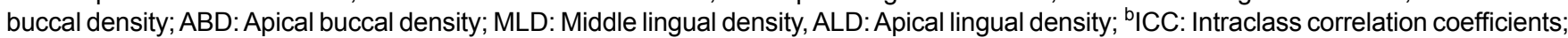
${ }^{c} p$-value: Comparison between two repetitions using paired $t$ tests, $p<0.05$ indicates statistical significance 
Table 3: Thickness and densities of alveolar bone in the three groups of malocclusion at the three assessed levels. One-way ANOVA tests are presented and significant differences in post-hoc tests are indicated

\begin{tabular}{|c|c|c|c|c|c|c|c|c|}
\hline \multirow{2}{*}{$\begin{array}{l}\text { Groups } \\
\text { Variables }^{a}\end{array}$} & \multicolumn{2}{|c|}{ Class I $(n=64)^{b}$} & \multicolumn{2}{|c|}{ Class II $(n=64)$} & \multicolumn{2}{|c|}{ Class III $(n=64)$} & \multirow[b]{2}{*}{$p$-value } & \multirow{2}{*}{$\begin{array}{c}\text { Tukey's tests } \\
\text { Statistically different groups }\end{array}$} \\
\hline & Mean & $S D^{C}$ & Mean & $S D$ & Mean & $S D$ & & \\
\hline CBT & 0.17 & 0.29 & 0.06 & 0.20 & 0.07 & 0.16 & 0.014 & I vs II \\
\hline MBT & 0.64 & 0.43 & 0.61 & 0.39 & 0.48 & 0.29 & 0.060 & - \\
\hline ABT & 3.64 & 1.18 & 3.71 & 1.53 & 2.37 & 1.51 & $<0.001$ & I vs III, II vs III \\
\hline CLT & 0.05 & 0.16 & 0.03 & 0.12 & 0.07 & 0.20 & 0.561 & - \\
\hline MLT & 1.31 & 0.81 & 1.09 & 0.41 & 1.06 & 0.64 & 0.059 & - \\
\hline ALT & 3.28 & 1.13 & 3.05 & 0.84 & 2.96 & 1.27 & 0.240 & - \\
\hline CBD & 255.16 & 385.20 & 44.16 & 144.74 & 181.64 & 381.48 & 0.001 & | vs || \\
\hline MBD & 958.83 & 319.86 & 909.38 & 310.52 & 986.96 & 372.83 & 0.418 & - \\
\hline ABD & 956.50 & 229.12 & 919.85 & 216.64 & 1043.88 & 242.18 & 0.008 & II vs III \\
\hline CLD & 59.91 & 179.75 & 51.52 & 162.69 & 56.39 & 160.69 & 0.961 & - \\
\hline MLD & 793.93 & 226.89 & 778.08 & 196.31 & 883.14 & 236.46 & 0.016 & II vs III \\
\hline ALD & 980.64 & 175.51 & 963.16 & 185.92 & 1042.97 & 202.97 & 0.060 & - \\
\hline
\end{tabular}

${ }^{\mathrm{a} C B T}$ : Cervical buccal thickness; MBT: Middle buccal thickness; ABT: Apical buccal thickness; CLT: Cervical lingual thickness; MLT: Middle lingual thickness; ALT: Apical lingual thickness; CBD: Cervical buccal density; MBD: Middle buccal density; ABD: Apical buccal density; CLD: Cervical lingual density; MLD: Middle lingual density, ALD: Apical lingual density; ${ }^{b}$ In each group, there were 16 patients $\times$

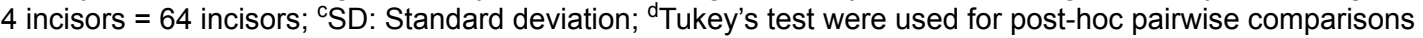

Table 4: Bone thickness on buccal and lingual surfaces of four incisors together with the $p$-values of significance tests

\begin{tabular}{|c|c|c|c|c|c|c|}
\hline & \multicolumn{2}{|c|}{ Class I $(n=64)^{a}$} & \multicolumn{2}{|c|}{ Class II $(n=64)$} & \multicolumn{2}{|c|}{ Class III $(n=64)$} \\
\hline & Buccal & Lingual & Buccal & Lingual & Buccal & Lingual \\
\hline \multirow[t]{2}{*}{ Cervical thickness } & 0.17 & 0.05 & 0.06 & 0.03 & 0.079 & 0.07 \\
\hline & $p=0.897$ & $N S^{b}$ & $p=0.875$ & NS & $p=0.779$ & NS \\
\hline \multirow[t]{2}{*}{ Middle thickness } & 0.64 & 1.31 & 0.61 & 1.09 & 0.48 & 1.06 \\
\hline & $p<0.001$ & & $p<0.001$ & & $p<0.001$ & \\
\hline \multirow[t]{2}{*}{ Apical thickness } & 3.64 & 3.28 & 3.70 & 3.05 & 2.37 & 2.96 \\
\hline & $p=0.083$ & NS & $p=0.003$ & & $p=0.019$ & \\
\hline
\end{tabular}

Values are presented as means and measured in millimeters. ${ }^{a}$ In each group, there were 16 patients $\times 4$ incisors $=64$ incisors; ${ }^{b} \mathrm{NS}$ : Not significant by applying paired t-tests; when $p<0.05$, this indicates statistical significance

Table 5: Bone density differences between three regions on buccal and lingual surfaces

\begin{tabular}{|c|c|c|c|c|c|}
\hline \multicolumn{6}{|c|}{ Comparisons on the buccal side of the lower incisors } \\
\hline Variable $^{a}$ & $C B D$ & $M B D$ & $A B D$ & $p$-value & Statistically different group ${ }^{c}$ \\
\hline Class I & 255.16 & 958.83 & 956.50 & $<0.001$ & $(\mathrm{C}$ vs $\mathrm{M})-(\mathrm{C} \text { vs } \mathrm{A})^{\mathrm{d}}$ \\
\hline Class II & 44.16 & 909.38 & 919.85 & $<0.001$ & $(\mathrm{C}$ vs $\mathrm{M})-(\mathrm{C}$ vs $\mathrm{A})$ \\
\hline Class III & 181.64 & 986.96 & 1043.88 & $<0.001$ & $(\mathrm{C}$ vs $\mathrm{M})-(\mathrm{C}$ vs $\mathrm{A})$ \\
\hline \multicolumn{6}{|c|}{ Comparison on the lingual side of the lower incisors } \\
\hline Variable $^{b}$ & $C L D$ & $M L D$ & $A L D$ & $p$-value & Statistically different group \\
\hline Class I & 59.91 & 793.93 & 980.64 & $>0.001$ & $(\mathrm{C}$ vs $\mathrm{M})-(\mathrm{C}$ vs $\mathrm{A})-(\mathrm{A}$ vs $\mathrm{M})$ \\
\hline Class II & 51.52 & 778.08 & 963.16 & $>0.001$ & $(\mathrm{C}$ vs $\mathrm{M})-(\mathrm{C}$ vs $\mathrm{A})-(\mathrm{A}$ vs $\mathrm{M})$ \\
\hline Class III & 56.39 & 883.14 & 1042.97 & $>0.001$ & $(\mathrm{C}$ vs $\mathrm{M})-(\mathrm{C}$ vs $\mathrm{A})-(\mathrm{A}$ vs $\mathrm{M})$ \\
\hline
\end{tabular}

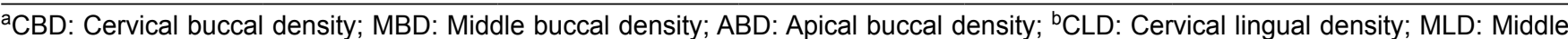
lingual density; ALD: Apical lingual density; ' $T$ Tukey's tests was used for post-hoc pairwise comparisons, when a significant difference is detected by one-way ANOVA; ${ }^{\mathrm{d}} \mathrm{C}$ : Cervical; M: Middle; A: Apical

between buccal and lingual surfaces at the apical regions only in class II and III patients. Apical buccal bone thickness was greater than lingual in class II patients $(p=0.003)$, while ABT was statistically smaller than ALT in the class III patients $(p=0.019)$. There were no significant differences between buccal and lingual surfaces at the cervical regions in the three groups. On the other hand, the middle lingual thickness (MLT) was statistically greater than that those of the middle buccal thickness (MBT) in the three groups $(p<0.001)$.

\section{Alveolar Bone Density}

It was noticed that cervical buccal density (CBD) was statistically lower in the class II group as compared to the class I and III groups ( $p=0.001$, Table 3$)$. When bone density was evaluated between the three vertical 
Evaluation of Bone Thickness and Density in the Lower Incisors' Region in Adults

Table 6: Pearson correlation coefficient values for the correlation between the bone thickness and bone density

\begin{tabular}{llllll}
\hline Variables $^{a}$ & $C B(T / D)^{b}$ & $M B(T / D)$ & $A B(T / D)$ & $C L(T / D)$ & $M L(T / D)$ \\
\hline Class I & $0.754^{* *}$ & $0.264^{*}$ & $-0.465^{* *}$ & $0.978^{* *}$ & 0.155 \\
Class II & $0.972^{* *}$ & $0.304^{*}$ & $-0.303^{*}$ & $0.970^{* *}$ & 0.196 \\
Class III & $0.889^{* *}$ & $0.278^{*}$ & $-0.368^{* *}$ & $0.822^{* *}$ & $-0.555^{* *}$ \\
\hline
\end{tabular}

${ }^{\mathrm{a} C B}$ : Cervical buccal; MB: Middle buccal; AB: Apical buccal; CL: Cervical lingual; ML: Middle lingual; AL: Apical lingual; ${ }^{b}$ (T/D) thickness correlated with density using Pearson's correlation coefficients; $R<0.9$, excellent correlation; $R=0.7-0.9$, strong correlation; $R=0.5-0.7$, moderate correlation; $R>0.5$, week correlation; $(+)$ Positive correlation; $(-)$ Negative correlation; ${ }^{*}$ Significant at $p>0.05$; ${ }^{\star \star}$ Significant at $p>0.01$

regions on both surfaces, it was found that bone density had a gradual increase from the cervical region towards the apical region buccally and lingually, as shown in Table 5. The buccal surface cervical region had low bone density and was given the quality grade of D4 according to Mish classification. Statistical differences were found between class I and II for the CBD and between class II and III for apical buccal density (ABD). Lingually, bone density was generally lower than buccal values. Cervical regions had low bone density in most incisors, bone density increased from the cervical to the apical regions, and the quality grade ranged from D4 to D2 according to Mish classification. Statistical differences were detected between class II and III patients for the middle lingual density (MLD) only.

\section{Correlations between Alveolar Bone Thickness and Density}

Values of Pearson correlation coefficients are shown in Table 6. At the cervical regions of the roots, R-values ranged from 0.75 to 0.95 , indicating strong to excellent positive association between bone thickness and density values on both buccal and lingual sides. On the other hand, weak positive correlation was found between bone density and thickness at the middle regions. In the apical region, week negative correlations were found on the buccal sides and moderate negative correlations were found on the lingual sides between bone density and thickness.

\section{DISCUSSION}

Even though there have been many studies about the effects of lower incisors' position and bone support on periodontal tissues during orthodontic movements, most of these studies have evaluated the dimensional characteristics of the supporting bone without evaluating its density. ${ }^{2,7,27}$ Alveolar bone density has been postulated to have a paramount effect on tooth movement, i.e. any increase in alveolar bone density offers more resistance to orthodontic tooth movement. ${ }^{28}$ This concept is supported by the fact that moving teeth is faster in children as compared to adults. The association between bone mineral density and periodontal problems has been studied. ${ }^{29}$ The only study that correlated alveolar bone thickness to density was published by Nauert et al; however, their study evaluated bone density using traditional CT scanning in skeletal class I patients. ${ }^{7}$ Therefore, the data regarding class II and III skeletal deformities is still lacking and this justified the current research project.

When bone thickness was evaluated, there were differences in the apical bone thickness between the three groups of skeletal malocclusion. Class II and I patients had greater values of apical buccal thickness than class III patients. The differences in thicknesses may be due to the variations of lower incisor inclination in the different sagittal patterns, patients as patients, with class III patients tend to have more retroclined lower incisor while patients with class II had more poroclined lower incisor. ${ }^{30,31}$ These results were similar to those obtained by Kook et al, who found differences in apical bone thickness in lower central incisors in class I and III patients. ${ }^{32}$ Apical thicknesses were greater at buccal surfaces in class I patients.

The current study also found differences in the cervical buccal thickness between class I, II and III patients, but the statistical differences were only observed between the class I and II patients. Class I patients had greater values of CBT than class II patients. Previous studies that compared alveolar bone thickness between different sagittal malocclusion focused only on the apical regions of the root with only one study comparing alveolar bone crest thicknesses between class I, II and III patients with different facial patterns. ${ }^{33}$ This study found that brachyfacial and dolicofacial patterns of class III had higher values of alveolar bone crest thickness than other classes of malocclusion. The difference between that study and the current one may be due to the different regions of bone that have been measured and their dependence on lateral cephalometric images with the known embedded magnification factor. ${ }^{34}$

There were also significant differences between the buccal and lingual surface for the four teeth in class II and III patients at the apical regions. Apical buccal thickness was greater than ALT in class II patients while it was statistically lower than ALT in class III patients. Similarly, Kim et al found that ABT in class III patients averaged $1.75 \mathrm{~mm}$ on the buccal aspect and $2.65 \mathrm{~mm}$ on the lingual 
(i.e. a mean of $1 \mathrm{~mm}$ difference approximately). ${ }^{32}$ In a study by Baysal et al, the ABT in class II patients averaged $3.00 \mathrm{~mm}$ on the buccal aspect and $1.82 \mathrm{~mm}$ on the lingual (i.e. a mean of $1.2 \mathrm{~mm}$ difference). ${ }^{18}$

The amount of alveolar bone thickness was significantly higher at the apical region as compared to the other two regions. These results were similar to the findings of Nauert et al and Nahm et al, who found gradual increase of bone thickness from the CEJ till the root apex level. ${ }^{7,35}$ This trend of gradual increase of alveolar bone thickness was also observed in the upper jaw by Nahas-Scocate et al, who evaluated bone thickness at three regions of the upper central incisors' root buccally and lingually using CBCT. ${ }^{36}$

Baysal et al found differences in the lower incisors' apical alveolar bone thickness when labial to lingual surfaces were compared. ${ }^{18}$ Buccal bone thickness was greater than lingual bone thickness in class II patients. The current study also showed differences in the ABT between the two surfaces in class II and III groups only. Apical bone thickness in class II patients was greater in the buccal surfaces, and in the lingual surfaces in class III. This may be attributed to the differences in incisors' inclinations between the two groups. In other words, in the class II malocclusion the proclined incisors made the roots' apices closer to the lingual cortices, whereas in class III malocclusion the opposite may have occurred.

This study confirmed the results of Nauert et al regarding bone density, as it increased from cervical regions to apical regions, and ranged from D4 in the cervical regions to D2 in the apical regions on both surfaces (i.e. in class III patients, the density on buccal surfaces ranged from $181.64 \mathrm{HU}$ at the cervical region to $986.96 \mathrm{HU}$ at the middle region and 1043.88 at the apical region). ${ }^{7}$ This finding was similar to those of Borges et al, who assessed cortical and spongious bone density of mandibular, alveolar and basal bone for orthodontic miniimplants' placement at different distances from alveolar crest; they found significant increase in mandibular bone density from anterior to posterior and from alveolar to basal bone. ${ }^{37}$ They found that bone density mean in mandibular jaw between the incisors was about $405 .{ }^{7}$ $\mathrm{HU}$ for the cancellous alveolar bone (i.e. 3-5 $\mathrm{mm}$ from the alveolar crest) and $435.5 \mathrm{HU}$ for the cancellous basal bone (i.e. $5-7 \mathrm{~mm}$ from the apex).

Furthermore, the current study found differences in bone density between the three groups; apical buccal bone density was greater in class III patients than in class II and I patients. This may be due to the adverse relation between apical bone density and thickness that we found; as the reduction in bone thickness is actually the reduction in the trabecular bone thickness, which is characterized with low densities as compared to the high cortical densities, and so class III group has the lowest ABT and greatest ABD.

Some correlations were found between bone density and thickness in different regions, i.e. at the cervical region strong correlation was found; whereas weak correlation was found at the middle regions and buccal apical regions, moderate correlation was also found at apical regions only in the lingual surfaces in the three groups.

These results were similar to those obtained by Nauert et al, but they found no correlation between bone density and thickness at the apical regions. ${ }^{7}$ This could be a result of their evaluation of density at $80 \%$ of the root within an area of $2 \mathrm{~mm}^{2}$ two dimensionally, whereas the current study evaluated the density two dimensionally within a line from the apex to the surface of the bone.

The differences between males and females were not studied in the current project, so it would be better to increase the sample size in a later study to detect gender influence on bony thickness and density. The present results show that thicknesses and densities differ in the buccal and lingual surfaces at different levels; so, before any orthodontic treatment, orthodontists should know the quality and quantity of patient's bone around the incisors to avoid any possible side effect. ${ }^{2}$

\section{CONCLUSION}

- There were differences in bone thickness and density at buccal and lingual surfaces of the four lower incisors' roots between different skeletal patterns' patients. Buccal apical thickness was greater in the class II and I patients than in the class III patients, whereas apical buccal bone density was greater in class III patients than in class II and I patients.

- Alveolar bone thickness and density increased from cervical to apical regions.

\section{REFERENCES}

1. Aasen TO, Espeland L. An approach to maintain orthodontic alignment of lower incisors without the use of retainers. Eur J Orthod 2005 Jun;27(3):209-214.

2. Yared KF, Zenobio EG, Pacheco W. Periodontal status of mandibular central incisors after orthodontic proclination in adults. Am J Orthod Dentofacial Orthop 2006 Jul;130(1):6e1-8.

3. Ten Hoeve A, Mulie RM. The effect of antero-postero incisor repositioning on the palatal cortex as studied with laminagraphy. J Clin Orthod 1976 Nov;10(11):804-822.

4. Melsen B. Biological reaction of alveolar bone to orthodontic tooth movement. Angle Orthod 1999 Apr;69(2):151-158.

5. Reitan K. Initial tissue behavior during apical root resorption. Angle Orthod 1974 Jan;44(1):68-82.

6. Handelman CS. The anterior alveolus: its importance in limiting orthodontic treatment and its influence on the occurrence of iatrogenic sequelae. Angle Orthod 1996;66(2): 95-109. 
7. Nauert K, Berg R. Evaluation of labio-lingual bony support of lower incisors in orthodontically untreated adults with the help of computed tomography. J Orofac Orthop 1999; 60(5):321-334.

8. Mulie RM, Hoeve AT. The limitations of tooth movement within the symphysis, studied with laminagraphy and standardized occlusal films. J Clin Orthod 1976 Dec;10(12): 882-893.

9. Fuhrmann R. Three-dimensional interpretation of labiolingual bone width of the lower incisors. Part II. J Orofac Orthop 1996 Jun;57(3):168-185.

10. Loubele M, Bogaerts R, Van Dijck E, Pauwels R, Vanheusden S, Suetens P, Marchal G, Sanderink G, Jacobs R. Comparison between effective radiation dose of CBCT and MSCT scanners for dentomaxillofacial applications. Eur J Radiol 2009 Sep; 71(3):461-468.

11. Fuhrmann R. Three-dimensional interpretation of periodontal lesions and remodeling during orthodontic treatment. Part III. J Orofac Orthop 1996 Aug;57(4):224-237.

12. Ludlow JB, Laster WS, See M, Bailey LJ, Hershey HG. Accuracy of measurements of mandibular anatomy in cone beam computed tomography images. Oral Surg Oral Med Oral Pathol Oral Radiol Endod 2007 Apr;103(4):534-542.

13. Kumar V, Ludlow JB, Mol A, Cevidanes L. Comparison of conventional and cone beam CT synthesized cephalograms. Dentomaxillofac Radiol 2007 Jul;36(5):263-269.

14. Wainwright WM. Faciolingual tooth movement: its influence on the root and cortical plate. Am J Orthod 1973 Sep;64(3): 278-302.

15. Wonglamsam $P$, Manosudprasit M, Godfrey K. Facio-lingual width of the alveolar base. Aust Orthod J 2003 Apr;19(1):1-11.

16. Bills DA, Handelman CS, BeGoleEA. Bimaxillary dentoalveolar protrusion: traits and orthodontic correction. Angle Orthod 2005 May;75(3):333-339.

17. Kim Y, Park JU, Kook YA. Alveolar bone loss around incisors in surgical skeletal Class III patients. Angle Orthod 2009 Jul;79(4):676-682.

18. Baysal A, Ucar FI, Buyuk SK, Ozer T, Uysal T. Alveolar bone thickness and lower incisor position in skeletal Class I and Class II malocclusions assessed with cone-beam computed tomography. Korean J Orthod 2013 Jun;43(3):134-140.

19. Jager A, Radlanski RJ, Taufall D, Klein C, Steinhofel N, Doler W. Quantitative determination of alveolar bone density using digital image analysis of microradiographs. Anat Anz 1990;170(3-4):171-179.

20. Adams JE. Quantitative computed tomography. Eur J Radiol 2009 Sep;71(3):415-424.

21. Hounsfield GN. Computerized transverse axial scanning (tomography): Part I. Description of system. Br J Radiol 1995 Nov;68(815):H166-172.

22. Lee S, Chung CK, Oh SH, Park SB. Correlation between bone mineral density measured by dual-energy X-ray absorptiometry and hounsfield units measured by diagnostic
CT in Lumbar Spine. J Korean Neurosurg Soc 2013 Nov;54(5): 384-389.

23. Faul F, Erdfelder E, Buchner A, Lang AG. Statistical power analyses using $G^{*}$ Power 3.1: tests for correlation and regression analyses. Behav Res Methods 2009 Nov;41(4):1149-1160.

24. Jacobson A. Application of the 'Wits' appraisal. Am J Orthod 1976 Aug;70(2):179-189.

25. Riedel RA. The relation of maxillary structures to cranium in malocclusion and in normal occlusion. The Angle Orthodontist 1952;22(3):142-145.

26. Misch CE. Bone classification, training keys to implant success. Dent Today 1989 May;8(4):39-44.

27. Djeu G, Hayes C, Zawaideh S. Correlation between mandibular central incisor proclination and gingival recession during fixed appliance therapy. Angle Orthod 2002 Jun;72(3):238-245.

28. Roberts, Eugene W. Orthodontics: Current Principles and Techniques. 4th ed. Bone physiology, metabolism, and biomechanics in orthodontic practice; St Louis: Mosby; 2005. p. 221-292.

29. Kim JW, Kong KA, Kim HY, Lee HS, Kim SJ, Lee SH, Sim KW, Kim MR, Lee JH. The association between bone mineral density and periodontitis in Korean adults (KNHANES 20082010). Oral Dis 2014 Sep;20(6):609-615.

30. Staudt CB, Kiliaridis S. Different skeletal types underlying Class III malocclusion in a random population. Am J Orthod Dentofacial Orthop 2009 Nov;136(5):715-721.

31. Al-Khateeb EA, Al-Khateeb SN. Anteroposterior and vertical components of class II division 1 and division 2 malocclusion. Angle Orthod 2009 Sep;79(5):859-866.

32. Kook YA, Kim G, Kim Y. Comparison of alveolar bone loss around incisors in normal occlusion samples and surgical skeletal class III patients. Angle Orthod 2012 Jul;82(4):645-652.

33. Gama A, Vedovello S, Vedovello-Filho M, Lucato AS, Junior MS. Evaluation of the alveolar process of mandibular incisor in class I, II and III Individuals with different facial patterns. UNOPAR Cient Ciênc Biol Saúde 2012;14(2):95-98.

34. Shokri A, Khajeh S, Khavid A. Evaluation of the accuracy of linear measurements on lateral cephalograms obtained from cone-beam computed tomography scans with digital lateral cephalometric radiography: an in vitro study. J Craniofac Surg 2014 Sep;25(5):1710-1713.

35. Nahm KY, Kang JH, Moon SC, Choi YS, Kook YA, Kim SH, Huang J. Alveolar bone loss around incisors in Class I bidentoalveolar protrusion patients: a retrospective threedimensional cone beam CT study. Dentomaxillofac Radiol 2012 Sep;41(6):481-488.

36. Nahas-Scocate AC, de Siqueira-Brandao A, Patel MP, LipiecXimenez ME, Chilvarquer I, do Valle-Corotti KM. Bone tissue amount related to upper incisors inclination. Angle Orthod 2014 Mar;84(2):279-285.

37. Borges MS, Mucha JN. Avaliação da densidade óssea para instalação de mini-implantes (Evaluation of bone density for mini-implant placement). Dent Press J Orthod 2010;15:e1-9. 